\title{
Sadness along with happiness: depression and satisfaction with life among postpartum women in Faisalabad
}

\author{
Nazia Yaqoob, Mahira Arshid, Zaib-un-nisa, Zanib Jabbar, Konain Fatima \\ Government College Women University Faisalabad, Pakistan
}

\begin{abstract}
The purpose of this study is to examine the relationship between demographic variables, Postpartum Depression (PPD) and Satisfaction With Life (SWL) in postpartum women of Faisalabad district. This is the first time that a study on postpartum women has been conducted in Faisalabad. In this cross-sectional study sample of 120 postpartum women (age range 20-40) has been collected from Saint Raphael Hospital Faisalabad by using convenience sample technique. Edinburgh Postnatal Depression Scale and Satisfaction with life Scale were used to measure PPD and SWL among postpartum women. A demographic form used to obtain demographic characteristics of the sample. Results show significant negative relationship between PPD and SWL among postpartum women of Faisalabad at $\mathrm{r}=0.659$ and 0.868 , respectively. Results also show significant positive relationship of age and language with postpartum depression at $\mathrm{r}=0.236$ and 0.316 ,
\end{abstract}

Correspondence: Mahira Arshid, Government College Women University Faisalabad, Pakistan.

Tel.: +9203216651071

E-mail: mahira1arshid@gmail.com

Key words: Postpartum; depression; satisfaction with life.

Acknowledgements: Authors would like to say thanks to all the people whose contribution played a role in the successful execution of this study.

Contribution: Conception and design; entry, analysis and interpretation of data and article writing: MA. Data collection, scale search and permission from author: Zaib-un-nisa, ZJ and KF. Drafting the article or revising it critically for important intellectual content and final approval of the version to be published: NY.

Conflict of interests: The authors declare no conflict of interest.

Ethics approval and consent to participate: Ethical approval and consent for publication have been obtained prior to publication.

Received for publication: 13 June 2020.

Revision received: 17 November 2020.

Accepted for publication: 19 November 2020.

This work is licensed under a Creative Commons AttributionNonCommercial 4.0 International License (CC BY-NC 4.0).

(C) Copyright: the Author(s), 2020

Licensee PAGEPress, Italy

Health Psychology Research 2020; 8:8960

doi:10.4081/hpr.2020.8960 respectively, and significant negative relationship of economic status, residence, hospital, and checkup pattern with postpartum depression with $\mathrm{r}=-0.365,-0.284,-0.192, \&-0.206$. Moreover, there is a non-significant relationship between SWL and any demographic variable. Results indicated that PPD and SWL are inversely linked in postpartum women at Faisalabad. And demographic variables are also linked with postpartum depression. Implications are also discussed in the conclusions.

\section{Introduction}

Postpartum Depression (PPD) is state of major depression that occurs after giving birth (Wisner, 2013). Symptoms are present for most of the day and last for at least 2 weeks. As many as 1 in every 7 women (14\%) suffers PPD. (Wisner, 2013) In a study of 209 women referred for major depression during or after pregnancy $11.5 \%$ reported start of depression during pregnancy, $66.5 \%$ reported start of depression within 6 weeks after childbirth (early postpartum), and $22 \%$ reported onset 6 weeks after childbirth (late postpartum). One woman reported onset of depression at more than 27 weeks after childbirth (Cox, Murray \& Chapman, 1993). One out of three women who suffers from psychological distress in late pregnancy with perceived social isolation will develop PPD (Nielsen, Videbech, Hedegaard, Dalby \& Secher, 2005). Women who are poor and have more psychological symptoms during pregnancy are more likely to remain depressed one year after giving birth (Rahman, 2007).

The Satisfaction with Life (SWL) means satisfaction with the person's life as a whole. According to Ruut Veenhoven "SWL is the degree to which a person positively evaluates the overall quality of his/her life as a whole. In other words, how much the person likes the life he/she leads" (1996). First-time mothers of advanced and very advanced age reported a slightly lower degree of SWL compared with the reference group of younger women, and the age-related effect was greatest when the child was three years of age (Aasheim, Waldenström, Rasmussen, Espehaug \& Schytt, 2014). General SWL is positively associated with education level, income level, and being married (Shichman \& Cooper, 1986). Presence of stress, depression and anxiety significantly decreases mental wellbeing and SWL during pregnancy. Increase in depression is highly responsible for rise in stress and anxiety among pregnant women (Alvi, Ali, Shah, Jabeen, Gul \& Afridi, 2018).

\section{Rationale of the study}

This study was conducted to observe the two parallel psychological states women face during postpartum phase. They are suffering from pain, but contentment is also observed in women at this stage of life, when a new member is added to the family. The purpose of this study is to find the relationship between demographic variables, PPD and SWL among women receiving treatment in tertiary health care units of Faisalabad district. 


\section{Objective}

The study aims to access significant relationship between demographic variables, PPD and SWL in women of Faisalabad district.

\section{Materials and Methods}

\section{Study design}

It was a cross-sectional observational study, conducted during September 2019 to January 2020.

\section{Participants}

Convenient sampling technique was used to select the target sample. The sample of 120 women who had given birth to children were taken from Saint Rapheal Hospital Faisalabad and the pregnant women who didn't give birth were excluded from this study. Post hoc power analysis was run using G*Power 3.0.10 software to obtain the sample power. Input parameters for two tail correlational point by serial were: effect size of 0.3 , alpha 0.05 and sample of 120 . Based on the above-mentioned assumptions, the desired sample size 120 with $\mathrm{df}=118$ contains a statistical power ( 1 -B err prob) 0.93 with critical $\mathrm{t}=1.98$.

\section{Measures}

The Edinburgh postnatal depression scale was a 10-item scale developed by Cox, Holden, and Sagovsky in 1987. It had been translated into 20 languages, but Urdu version is used in this study. This scale has a reliability of 0.86 and in this study it had a reliability of .659. A mother checks off one of four possible answers that is closest to how she has felt during the past weeks. Responses are scored $0,1,2$ and 3 based on the seriousness of the symptom. Items 3, 5 to 10 are reverse scored (i.e., 3, 2, 1, and 0). The total score is found by adding together the scores for each of the 10 items. Mothers scoring above 12 or 13 are likely to be suffering from depression and should seek medical attention (Cox et al., 1987).

The Satisfaction With Life Scale was developed by Diener, Emmons, Larsen and Griffin in 1985. The Urdu version of this scale had been used in this study. This scale had the reliability of 0.82 but in this study it had the reliability of .868 . It is a 5-item scale designed to measure global cognitive judgments of one's life satisfaction. Participants indicate how much they agree or disagree with each of the 5 items using a 7-point Likert scale that ranges from 7 strongly agree to 1 strongly disagree. Scoring is continuous (sum up scores on each item), minimum score can be 5 (showing extremely dissatisfied) and maximum score can be 35 (showing extremely satisfied) (Diener et al., 1985).

\section{Procedure}

Both measuring scales were taken from online websites. After obtaining the permission from authors, the scales were used to col- lect data from participants from Faisalabad district. Participants who fall on inclusion criteria (mothers who had given birth to children) were told the purpose of the study and they were assured that their provided information would be kept confidential.

\section{Data analysis}

IBM SPSS Statistics version 21 was used for data entry and analysis of the data.

\section{Results}

The present study was conducted to access the relationship between demographic variables, PPD and SWL among postpartum women in Faisalabad. Reliability index of study instrument are stated in Table 1. Pearson product moment coefficient correlation was used to examine the correlation between PPD and SWL among postpartum women. Demographic characteristics of the study sample given in Table 2 .

Descriptive statistics given in Table 2 indicates that sample included postpartum women age ranging from 20 to 50 years. The sample was taken from different economic statuses and casts. Most of the women in our the sample lived in a joint family system and had an intermediate level of education. The majority of the women in the sample were Muslims, and lived in Faisalabad city. The majority of them were Urdu and Punjabi speaking. The majority of the women $70.8 \%$ in the sample did not have any disease, although $21.7 \%$ had blood pressure issues and $7.5 \%$ had diabetes. The sample was taken mostly from private hospital that was $97.5 \%$ and $83.3 \%$ of the women had 1 to 3 children and only $16.7 \%$ have $4-6$ children. The majority of the sample had a 20 to 50 thousand rupees monthly income, and the duration of marriage mostly lied in the 1-10 years range. Most of the women followed a monthly check up schedule and had continued their medication.

The reliability of the scales tabulated in Table 1 stated that Edinburgh Postnatal Depression Scale (EPNDS) and Satisfaction with life Scale (SWLS) had Chronbach's Alpha value 0.659 and 0.868 , respectively. EPNDS and SWLS had 10 and 5 number of items, respectively, with means of 25.43 and 28.84 .

There is a significant negative relationship between PPD and SWL ( $r=-0.410, p<0.01)$ among postpartum women of Faisalabad.

Table 3 indicates that a significant negative correlation exists between PPD and SWL in postpartum women of Faisalabad district. There is a significant positive relationship between age and depression, cast and religion, cast and duration of marriage, economic status and residence, economic status and checkup pattern, family system and duration of marriage, education and residence, education and monthly income, religion and language, residence and checkup pattern, language and depression, and number of children and duration of marriage. There is significant negative relationship between age and economic status, residence, language, any disease; economic status and depression; religion and hospital; residence and language, depression; language and any disease, number of children, monthly income; any disease and duration of

Table 1. Reliability index, number of items, scoring range and means values of scales.

\begin{tabular}{lcccc} 
Name of Scales & Number of items & Scoring range & $\alpha$ & Mean \\
EPNDS & 10 & $1-30$ & 0.659 & 25.43 \\
SWLS & 5 & $5-35$ & 0.868 & 28.84 \\
\hline
\end{tabular}

EPNDS=Edinburgh Postnatal Depression Scale; SWLS=Satisfaction with Life Scale. 
marriage; hospital and depression; duration of marriage and checkup pattern; checkup pattern and depression.

\section{Discussion}

A study was conducted in order to find relations among prenatal role quality, SWL, and dual earners parent's and PPD. In this study they have tested a hypothesis that greater prenatal work family strain, role disparity and intensity, and less life satisfaction would lead to greater PPD. Results have indicated that poorer role quality and less life satisfaction are associated with postnatal depression (Hall \& Long, 2007).

Another study was conducted in Karachi concluded a significant negative relationship of scores of PPD with SWL and marital satisfaction. Hence it seems that SWL plays significant role in PPD (Munaf \& Siddiqui, 2013).

A study on depression and SWL was conducted in Australia and Nepal. The results show that no significant differences were found in depressive symptomatology. Australian respondents reported significantly higher SWL than Nepalese. A moderate significant inverse relationship was found between depressive symptoms and SWL in the Australian respondents, with a smaller significant inverse relationship observed among the Nepalese respondents. The findings suggest that the experience of depressive symptoms may be partially independent of SWL for this Nepalese sample (Simpson, Schumaker, Dorahy, \& Shrestha, 1996). May be some other factors play role in partial independence of depressive symptoms from SWL, whereas, SWL and depressive symptoms have significant inverse relationship in Australia (Simpson et al., 1996).

A study examined the contributions of demographic variables, antepartum depressive symptoms, and sources of stress to level of PPD. The Beck Depression Inventory (BDI) and demographic data sheet were administered to 69 women during the eighth month of pregnancy. One month after delivery, subjects completed the post $\square$ delivery questionnaire and BDI. A stratified hierarchical regression analysis revealed that marital status, antepartum depressive symptoms, and difficulty of pregnancy predicted level of PPD. Somatic stressors of pregnancy may trigger depressive symptoms that persist after childbirth, particularly in unmarried mothers (Stevens, and Lum, 1990).

A survey was conducted to investigate the prevalence of PPD symptoms among Finnish mothers and to ascertain the relationship with sociodemographic factors in mothers. A sample of 1000 families at 2 months postnatal was studied by mailing the Edinburgh Postnatal Depression Scale to mothers and a questionnaire on demographic characteristics to mothers and fathers. The response rate was $39 \%$. The data were examined by means of frequency and percentage distributions. Connections were examined using Spearman correlation coefficient and analysis of variance. In all, 373 mothers and 314 fathers took part in the study. Fifty $\square$ five (13\%) mothers had depressive symptoms. Results show that the number of pregnancies, deliveries or children, the mode of delivery or the mother's age were not associated with depressive symptoms. However, mothers who had depressive symptoms had fewer years of education, shorter duration of breast $\square$ feeding and were more dissatisfied with family life compared with mothers who exhibited no depressive symptomatology. The families of mothers with depressive symptoms had also experienced more problems and changes having a profound impact on the family compared with other mothers (Tammentie, Tarkka, Åstedt $\square$ Kurki \& Paavilainen, 2002).
Table 2. Frequencies and percentages of demographic variables of postpartum women $(\mathrm{N}=120)$.

\begin{tabular}{lc} 
Variable & F (\%) \\
Age & \\
$20-29$ & $75(62.5)$ \\
$30-39$ & $38(3.117)$ \\
$40-50$ & $7(5.8)$ \\
Cast & \\
Rajpoot & $25(20.8)$ \\
Arain & $30(25.0)$ \\
Jut & $23(19.2)$ \\
Ansari & $12(10)$ \\
Malik & $11(9.2)$ \\
Any else & $19(15.8)$ \\
\hline
\end{tabular}

\section{Economic status}

$\begin{array}{ll}\text { Low } & 12(10) \\ \text { High } & 12(10) \\ \text { Middle } & 96(80)\end{array}$

\begin{tabular}{ll} 
Family system & \\
Joint & $74(61.7)$ \\
Nuclear & $46(38.3)$ \\
\hline
\end{tabular}

Education in Gender

Less than 10th Grade $\quad 37(30.8)$

10-12th Grade $\quad 51(42.5)$

13-14th Grade $21(17.5)$

15-16th Grade $\quad 11(9.2)$

\begin{tabular}{lc} 
Religion & $117(97.5)$ \\
Muslim & $3(2.5)$ \\
Non Muslim & $11(9.2)$ \\
\hline
\end{tabular}

Residence

Village $42(35)$

City 78 (65)

\begin{tabular}{ll} 
Language & \\
Urdu & $76(63.3)$ \\
Punjabi & $44(36.7)$ \\
\hline
\end{tabular}

Any disease

Diabetes $9(7.5)$

Blood pressure $\quad 26$ (21.7)

None $85(70.8)$

\begin{tabular}{lc} 
Hospital & $3(2.5)$ \\
Public & $117(97.5)$ \\
Private & \\
\hline
\end{tabular}

Number of children

$1-3 \quad 100(83.3)$

4-6 20 (16.7)

\begin{tabular}{lc} 
Monthly income in thousands & \\
$20-50$ & $86(71.7)$ \\
$50-90$ & $26(21.7)$ \\
90 plus & $9(6.7)$ \\
\hline
\end{tabular}

Duration of marriage in years

$\begin{array}{lc}1-10 & 94(78.3) \\ 11-20 & 25(20.8) \\ 21 \text { plus } & 1(8)\end{array}$

$\begin{array}{lc}\text { Follow-up routine } & \\ \text { Weekly } & 17(14.2) \\ \text { Monthly } & 103(85.8)\end{array}$

Medicine intake

Continue $\quad 86$ (71.7)

Not anymore $34(28.3)$ 
Table 3. Correlation between demographic variables, Postpartum Depression and Satisfaction with Life among postpartum women of Faisalabad.

\begin{tabular}{|c|c|c|c|c|c|c|c|c|c|c|c|c|c|c|c|c|c|}
\hline Variables & A & B & C & D & E & $\mathrm{F}$ & G & $\mathrm{H}$ & I & $\mathrm{J}$ & $\mathrm{K}$ & L & M & $\mathbf{N}$ & 0 & $\mathbf{P}$ & Q \\
\hline A & 1 & & & & & & & & & & & & & & & & \\
\hline B & 0.14 & 1 & & & & & & & & & & & & & & & \\
\hline C & $-0.18^{*}$ & 0.05 & 1 & & & & & & & & & & & & & & \\
\hline D & $0.26^{* *}$ & 0.18 & 0.08 & 1 & & & & & & & & & & & & & \\
\hline E & 0.07 & 0.00 & 0.08 & -0.04 & 1 & & & & & & & & & & & & \\
\hline $\mathrm{F}$ & -0.03 & $0.21^{*}$ & 0.08 & 0.09 & 0.05 & 1 & & & & & & & & & & & \\
\hline $\mathrm{G}$ & $-0.20 *$ & -0.04 & $0.20 *$ & 0.08 & $0.19 *$ & 0.01 & 1 & & & & & & & & & & \\
\hline $\mathrm{H}$ & $-0.20^{*}$ & 0.04 & -0.06 & -0.09 & -0.08 & $0.20^{*}$ & $-0.55^{* *}$ & 1 & & & & & & & & & \\
\hline I & $-0.20^{*}$ & 0.17 & 0.14 & -0.06 & 0.09 & -0.16 & 0.16 & $-0.19 *$ & 1 & & & & & & & & \\
\hline $\mathrm{J}$ & 0.03 & -0.02 & 0.18 & -0.09 & 0.13 & $-0.32 * *$ & -0.01 & -0.09 & 0.08 & 1 & & & & & & & \\
\hline $\mathrm{K}$ & $0.24^{* *}$ & 0.13 & 0.04 & 0.15 & -0.02 & 0.07 & 0.14 & $-0.21 *$ & 0.05 & 0.07 & 1 & & & & & & \\
\hline L & -0.10 & -0.01 & -0.16 & -0.00 & $0.24^{* *}$ & -0.09 & -0.17 & $-0.25^{* *}$ & 0.08 & 0.09 & 0.04 & 1 & & & & & \\
\hline $\mathrm{M}$ & $0.52^{* *}$ & $0.18 *$ & -.12 & $0.26^{* *}$ & 0.06 & 0.04 & -0.10 & .010 & $-0.19 *$ & 0.08 & $0.23^{*}$ & 0.02 & 1 & & & & \\
\hline $\mathrm{N}$ & -0.11 & 0.09 & $.18^{*}$ & 0.08 & 0.02 & 0.07 & $0.20^{*}$ & -0.07 & 0.03 & 0.09 & 0.05 & -.08 & $-0.28 * *$ & 1 & & & \\
\hline 0 & -0.02 & 0.05 & 0.01 & 0.15 & 0.03 & 0.02 & 0.15 & -0.00 & 0.01 & -0.02 & -.08 & -.09 & -0.15 & -0.01 & 1 & & \\
\hline $\mathrm{P}$ & -0.18 & 0.05 & 0.08 & 0.07 & -0.08 & -0.03 & 0.17 & -0.10 & 0.04 & -0.06 & -.07 & -.13 & 0.02 & 0.03 & 0.13 & 1 & \\
\hline$Q$ & $0.24 * *$ & 0.00 & $-0.37 * *$ & 0.02 & 0.16 & 0.14 & $-0.28 * *$ & $0.32 * *$ & -0.15 & $-0.19 *$ & -.02 & .04 & 0.09 & $-0.21^{*}$ & 0.05 & $-0.41^{* *}$ & 1 \\
\hline
\end{tabular}

$\mathrm{A}=$ Age; $\mathrm{B}=$ Cast; $\mathrm{C}=$ Economic status; $\mathrm{D}=$ Family system; $\mathrm{E}=$ Education; $\mathrm{F}=$ Religion; $\mathrm{G}=$ Residence; H=Language; $\mathrm{I}=$ Any disease; $\mathrm{J}=$ Hospital; $\mathrm{K}=$ Number of children; $\mathrm{L}=$ Monthly income; $\mathrm{M}=$ Duration of marriage; $\mathrm{N}=$ Checkup pattern; $\mathrm{O}=$ Medicine intake; $\mathrm{P}=$ Satisfaction with life scale; $\mathrm{Q}=$ Edinburgh postnatal depression scale. ${ }^{*} \mathrm{p}<0.05$ and ${ }^{* *} \mathrm{p}<0.01$.

In rural areas, there was a non significant gradient of risk: women with less connection to larger urban centres were at greater risk of postpartum depression than women in areas with greater connection (Vigod et al., 2013).

The results of a study clearly show a significant increase in life satisfaction in the postpartum period $(p<0.0001)$. An important correlate of life satisfaction in the third trimester of pregnancy is social support received $(\mathrm{p}<0.0001)$. During pregnancy such a correlate is emotional support received, and in the postnatal periodinstrumental support received. An increase in instrumental support received $(\mathrm{p}=0.031)$ and informational $(\mathrm{p}=0.013)$ has been observed in the postpartum period (Gebuza, Kaźmierczak, Mieczkowska, Gierszewska, \& Kotzbach, 2014).

\section{Conclusions}

There is a significant negative relationship between PPD and SWL among postpartum women of Faisalabad district. This shows that higher the PPD lower the level of SWL among postpartum women of Faisalabad district. There is a significant positive relationship between age and depression, cast and religion, cast and duration of marriage, economic status and residence, economic status and checkup pattern, family system and duration of marriage, education and residence, education and monthly income, religion and language, residence and checkup pattern, language and depression, and number of children and duration of marriage. There is significant negative relationship between age and economic status, age and residence, age and language, age and any disease, economic status and depression, religion and hospital, residence and language, residence and depression, language and any disease, language and number of children, language and monthly income, any disease and duration of marriage, hospital and depression, duration of marriage and checkup pattern, checkup pattern and depression, This study helps physicians in order to understand the psychological aspects of postpartum patients while prescribing them medicine.

\section{References}

Aasheim, V., Waldenström, U., Rasmussen, S., Espehaug, B., \& Schytt, E., (2014). Satisfaction with life during pregnancy and early motherhood in first-time mothers of advanced age: a population-based longitudinal study. BMC Pregnancy and Childbirth, 14(86).

Alvi, S.M., Ali, S.A., Shah, R.A., Jabeen, T., Gul, N., \& Afridi, M. (2018). Internalizing psychological problems as predictor of mental wellbeing and life satisfaction among pregnant women. Pakistan Journal of Physiology, 14(3).

Cox, J.L., Murray D., \& Chapman G. (1993). A controlled study of the onset, duration and prevalence of postnatal depression. British Journal of Psychiatry; 163:27-31.

Cox, J.L., Holden, J.M., \& Sagovsky, R. (1987). Detection of postnatal depression: Development of the 10-item Edinburgh Postnatal Depression Scalee. British Journal of Psychiatry, 150:782-786

Diener, E., Emmons, R. A., Larsen, R. J., \& Griffin, S. (1985). The Satisfaction with Life Scale. Journal of Personality Assessment, 49, 71-75.

Gebuza, G., Kaźmierczak, M., Mieczkowska, E., Gierszewska, M., \& Kotzbach, R. (2014). Life satisfaction and social support received by women in the perinatal period. Advances in Clinical and Experimental Medicine, 23(4), 611-619.

Hall, W.A., \& Long, B.C., (2007) Relations among prenatal role quality, life satisfaction, and dual earners parent's and postpartum depression. Journal of Prenatal and Perinatal Psychology and Health, 21(3). 
Munaf, S., \& Siddiqui, B., (2013). Relationship of post-natal depression with life and marital satisfaction and its comparison in joint and nuclear family system. Social and Behavioral Sciences, 84, 733-738.

Nielsen, D., Videbech, P., Hedegaard, M., Dalby, J., \& Secher, N.J.,(2005). Postpartum depression: identification of women at risk. An International Journal of Obstetrics and Gynaecology, 107, 1210-1217.

Pfost, K.S., Stevens, M.J., and Lum, C.U., (1990) The relationship of demographic variables, antepartum depression, and stress to postpartum depression, Psychodynamics and Psychopathology, 46(5), 588-92.

Rahman, A. (2007, June) Outcome of prenatal depression and risk factors associated with persistence in the first postnatal year: Prospective study from Rawalpindi, Pakistan. Journal of Affective Disorders, 100(1-3), 115-121.
Shichman, S., Cooper, E., (1984) Life Satisfaction and Sex-Role Concept, Sex Roles 11, 227-240.

Simpson, P.L., Schumaker, J.F., Dorahy, M.J, \& Shrestha, S.N. (1996) Depression and Life Satisfaction in Nepal and Australia. The Journal of Social Psychology, 136(6), 783-790.

Tammentie, T., Tarkka, M.T., Kurki, P.A, \& Paavilainen, E., (2002). Sociodemographic factors of families related to postnatal depressive symptoms of mothers. International Journal of Nursing Practice, 10(1016).

Vigod, S.N., Tarasoff, L.A., Bryja, B. Dennis, C.L., Yudin, M.H., \& Ross, L.E. (2013). Relation between place of residence and postpartum depression. Canadian Medical Association Journal, 185(13) 1129-1135.

Wisner, K.L., (2013). Onset timing, thoughts of self-harm, and diagnoses in postpartum women with screen-positive depression findings. JAMA Psychiatry, 70(5), 490-8. 